\title{
Proven infection-related sepsis induces a differential stress response early after ICU admission
}

\author{
Olivier Lesur*1,2, Jean-Francois Roussy1,2, Frederic Chagnon², Nicole Gallo-Payet³, Robert Dumaine³, Philippe Sarret³, \\ Ahmed Chraibi ${ }^{3}$, Lucie Chouinard 3 and Bruno Hogue ${ }^{2}$
}

\begin{abstract}
Introduction: Neuropeptides arginine-vasopressin (AVP), apelin (APL), and stromal-derived factor-1a (SDF-1a) are involved in the dysfunction of the corticotropic axis observed in septic ICU patients. Study aims were: (i) to portray a distinctive stress-related neuro-corticotropic systemic profile of early sepsis, (ii) to propose a combination data score, for aiding ICU physicians in diagnosing sepsis on admission.

Methods: This prospective one-center observational study was carried out in a medical intensive care unit (MICU), tertiary teaching hospital. Seventy-four out of 112 critically ill patients exhibiting systemic inflammatory response syndrome (SIRS) were divided into two groups: proven sepsis and non sepsis, based on post hoc analysis of microbiological criteria and final diagnosis, and compared to healthy volunteers $(n=14)$. A single blood sampling was performed on admission for measurements of AVP, copeptin, APL, SDF-1a, adrenocorticotropic hormone (ACTH), cortisol baseline and post-stimulation, and procalcitonin (PCT).

Results: Blood baseline ACTH/cortisol ratio was lower and copeptin higher in septic vs. nonseptic patients. SDF-1 a was further increased in septic patients vs. normal patients. Cortisol baseline, ACTH, PCT, APACHE II and sepsis scores, and shock on admission, were independent predictors of sepsis diagnosis upon admission. Using the three first aforementioned categorical bio-parameters, a probability score for predicting sepsis yielded an area under the Receiver Operating Curve (ROC) curves better than sepsis score or PCT alone (0.903 vs 0.727 and 0.726: $P=0.005$ and $P<0.04$, respectively).

Conclusions: The stress response of early admitted ICU patients is different in septic vs. non-septic conditions. A proposed combination of variable score analyses will tentatively help in refining bedside diagnostic tools to efficiently diagnose sepsis after further validation.
\end{abstract}

\section{Introduction}

Severe sepsis and septic shock are the most common causes of death in intensive care units (ICU) with a mortality rate ranging from 30 to $70 \%$ [1]. Most of these related deaths result from multiple organ dysfunction/ failure occurring in advanced stages of septic shock [2]. During septic shock, the hypothalamo-pituitary-adrenal (HPA) axis is also dysfunctional and the neuroendocrine stress response system is disrupted [2,3]. One of the best

* Correspondence: olivier.lesur@USherbrooke.ca

1 Soins intensifs médicaux, département de Médecine, Université de Sherbrooke, 3001, 12th Avenue Nord, Sherbrooke, QC J1H 5N4, Canada Full list of author information is available at the end of the article examples is the concept of relative adrenal insufficiency which has recently been denominated CIRCI (critical illness-related corticosteroid insufficiency) [4]. Annane et al. first demonstrated that septic shock patients exhibiting a blunted dynamic cortisol response to corticotropin had more vasopressor-unresponsive shock and a higher 28 -day mortality rate $[5,6]$. The Corticosteroid therapy of septic shock (CORTICUS) study confirmed almost half of septic patients exhibited an inappropriate dynamic response to corticotropin, and that septic shock was more quickly reversed for those receiving hydrocortisone [7].

Neuropeptides of the posterior pituitary area may be actively committed in the regulation of the aforemen- 
tioned corticotropic axis. Indeed, arginine-vasopressin (AVP) heightens hypothalamic sensitivity to corticotrophin-releasing hormone (CRH), thereby increasing $\mathrm{ACTH}$ release and cortisol production, and improves hemodynamics during sepsis [8,9]. Apelin (APL), a new endogenously released peptide discovered in 1998 and co-expressed within vasopressinergic neurons, was found to be implicated in the up-regulation of ACTH pituitary secretion [9-11]. Furthermore, the stromal-derived factor- $1 \alpha$ (SDF- $1 \alpha)$, a member of the chemokine family recently reported to co-localize with AVP in the magnocellular neurons of the hypothalamic supraoptic (SON) and paraventricular nuclei (PVN), may potentially interfere with AVP functions [12].

It is unknown whether the stress response to ICU admission leads to a uniform pathway, irrespective if the cause of admission is sepsis-related or not, whether neuropeptide release can interact with the neighboring corticotrope axis in stress conditions, and if the outcome can be affected by their ensuing cross-talks. In parallel, the search for biomarkers to improve diagnostic accuracy in systemic infections is especially relevant in an ICU setting. Recent reports have emphasized the value of measuring blood procalcitonin (PCT), C-reactive protein in the initial diagnostic assessment of systemic infection [13]. Copeptin, a stable moiety of pre-pro-AVP is also considered as a valuable marker of severe sepsis [14-16]. However, there is still room for improvement in establishing a robust protocol, especially with regards to the imperfect predictive value of PCT for sepsis-specific diagnosis.

The main hypothesis is that a differential molecular profile can be observed depending on the stressor's origin, with correlations evoking cross-regulation, and that the related initial blood profile can predict the diagnosis of sepsis. A primary objective of the present study was to outline a profile of neuro-corticotropic systemic blood content in two stress causative groups of early admitted MICU patients and to tentatively delineate differential response patterns. A secondary objective was to determine, in a post hoc analysis, the best interpretative risk assessment score, including an overview of neuro-corticotropic molecules, which could further support conventional microbiological samples to help ICU physicians in the early diagnosis of sepsis upon MICU admission.

\section{Materials and methods Patients}

This study was conducted between December 2007 and 2008 in a 16-bed medical and coronary intensive care unit (MICU) of a tertiary university teaching hospital admitting 1,000 to 1,500 patients/year.

Seventy-four out of the 112 screened patients exhibiting systemic inflammatory response syndrome (SIRS) were consecutively included within the first 24 hours of admission to MICU (Figure 1). From this cohort, two groups of patients were compared to one control group: A first group (so called sepsis) of patients demonstrating severe sepsis or septic shock according to criteria of the $2001 \mathrm{SCCM} / \mathrm{ESICM} / \mathrm{ACCP} / \mathrm{ATS} /$ SIS International Sepsis Definitions Conference and surviving sepsis campaign guidelines $[17,18]$, further proven by microbiological evidence of infection; a second group (so called non-sepsis, as an internal control stressed group) comprised of patients admitted for critical illness with a clearly documented noninfectious primary cause and without evidence of infection; a third group of healthy gender- and age-matched non-hospitalized volunteers was subsequently recruited.

The APACHE II score, and in-hospital mortality were also recorded for MICU patients. In addition, a sepsis score was post hoc calculated for the sepsis group, taking into account: general; inflammatory (including PCT); hemodynamic; organ dysfunction; and tissue perfusion variables (maximum 19 points, scheme 1 in [18]).

Group allocation, with respect to microbiological data; and final primary diagnosis, was performed blindly to biomarkers' results and sepsis score calculation and post hoc validated after in-hospital file examination by three independent researchers. Based on the primary reason of admission; five re-allocations per group $(n=10,13.5 \%)$ were processed after file analysis.

Patients were excluded if under 18 years old, pregnant, having contra-indications to receiving corticotropin, treated in the past three months with corticosteroids, requiring administration of corticosteroids; drug(s) associated with corticosteroid insufficiency (for example, etomidate); or exogenous AVP infusion in the present admission. Patients in septic shock requiring corticosteroids were not excluded because they were sampled before the treatment initiation.

This study was approved by the institutional review board and the ethics committee of the Sherbrooke University Medical Center. Consents were obtained directly from patients or next of kin after permission from the onduty ICU physician and specific approval for adrenal gland sampling of organ donors.

\section{Blood collection in critically ill patients}

Blood samplings were always performed between 9 and 11 AM. A first sampling was collected in iced aprotinin (0.33 U, Sigma-Aldrich, St. Louis, MO, USA) -containing tubes, and plasma preserved for AVP, copeptin, APL, ACTH and SDF- $1 \alpha$ CXCL12 measurements. Remaining blood was used for establishing cortisol baseline after which $250 \mu \mathrm{g}$ of cosyntropin/corticotropin (Cortrosyn', Amphastar Pharmaceuticals, Scarborough, ONT, Canada) was injected intravenously, and blood was retrieved 


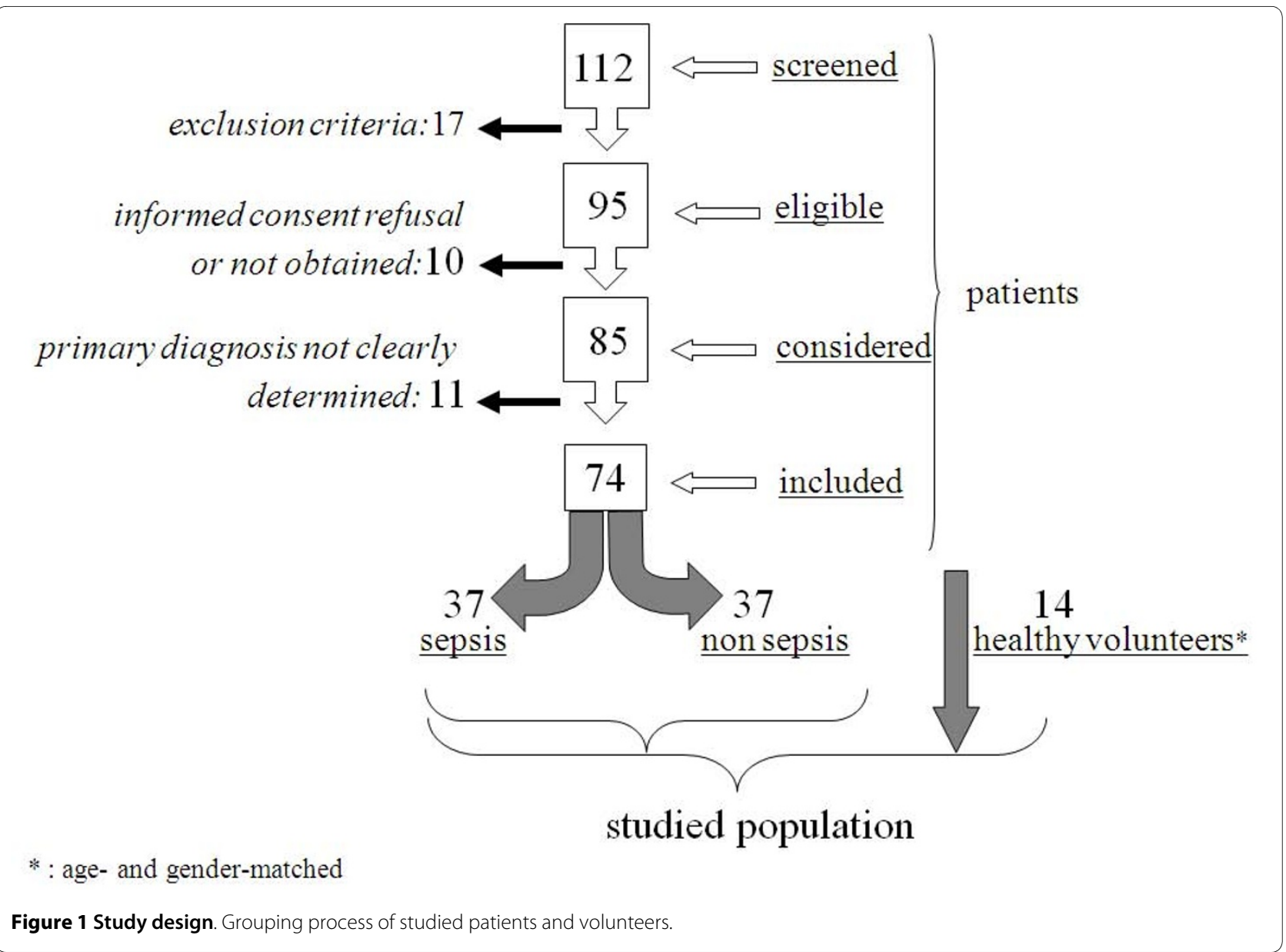

30 minutes and 60 minutes later. Serum lactate and albumin values were also quantified on the first day of admission, as described previously [19].

\section{Determination of blood cortisol and ACTH concentrations}

Blood cortisol and ACTH measurements were performed as detailed in Table 1 . The $\Delta$ max cortisol after corticotropin challenge was determined as a marker of adrenal gland reserve response by subtracting the cortisol baseline value from the 60 minutes cortisol value. CIRCI was defined as $\Delta \max \leq 248 \mathrm{nMol} / \mathrm{L}$ or cortisol baseline $\leq 276$ $\mathrm{nMol} / \mathrm{L}$, as recommended [4].

\section{Determination of circulating neuropeptide and procalcitonin $(\mathrm{PCT})$ concentrations}

APL, copeptin, AVP, SDF-1 $\alpha$ and PCT blood contents were measured as detailed in Table 1.

\section{Immunofluorescence imaging of human adrenal glands}

Tissue sections were incubated with polyclonal goat anti$\mathrm{C}-\mathrm{X}-\mathrm{C}$ chemokine receptor type 4 (CXCR4), the chemokine receptor for CXCL12/SDF-1 $\alpha$ (sc-6190, 1:50; Santa Cruz Biotechnology, Santa Cruz, CA, USA), and polyclonal rabbit anti-cytochrome P450 steroid 21hydroxylase (P450c21), a key-limiting enzyme of the adrenal cortex for 11-deoxycortisol and -deoxycorticosterone production, (1:100; gift of Walter L. Miller, University of California, San Francisco, CA, USA) in 1.5\% donkey serum (Zymed, San Francisco, CA, USA). AntiCXCR4 staining was revealed with FITC-conjugated donkey anti-goat IgG and P450c21 with TRITC-conjugated donkey anti-rabbit IgG (1:50; Santa Cruz Biotechnology for both secondary antibodies) in $2 \%$ donkey serum. Sections were analyzed using an Axioskop 2 fluorescence microscope (Carl Zeiss, Inc, Thornwood, NY, USA).

\section{Statistical analysis}

Results are presented as median and interquartile ranges in the illustrations, and as mean \pm SD in Table 2 (with exception to lactates). Categorical variables are presented as frequency and percentage. Baseline characteristics of septic and nonseptic patients were compared using the Mann-Whitney $U$ test for quantitative variables. A Kruskal-Wallis test with Dunn's multiple comparisons post-test was used for subset analysis and comparisons 
Table 1: Specifications of neuropeptide/protein blood dosages

\begin{tabular}{|c|c|c|c|c|c|}
\hline Protein/Peptide & Extraction & Assay & Source & Sensitivity & Range \\
\hline Cortisol & None & ADVIA Centaur system & $\begin{array}{l}\text { Siemens Medical } \\
\text { Solutions } \\
\text { Diagnostics, } \\
\text { Tarrytown, NY, USA. }\end{array}$ & 5.5 to $2069 \mathrm{nMol} / \mathrm{L}$ & 85 to $618 \mathrm{nMol} / \mathrm{L}$ \\
\hline ACTH & None & ImmuChem TM 125I RIA kit & $\begin{array}{l}\text { MP Biomedicals, LLC, } \\
\text { Diagnostics Division, } \\
\text { Orangeburg, NY, USA. }\end{array}$ & $5.7 \mathrm{pg} / \mathrm{mL}$ & 0 to $1000 \mathrm{pg} / \mathrm{mL}$ \\
\hline Apelin & $\begin{array}{l}\text { C-18 SEP-column and } \\
\text { lyophilisation }\end{array}$ & $\begin{array}{l}\text { Apelin-12 enzyme } \\
\text { immunoassay kit }\end{array}$ & $\begin{array}{l}\text { Phoenix } \\
\text { Pharmaceuticals Inc, } \\
\text { Burlingame, } \\
\text { California, USA. }\end{array}$ & $0.07 \mathrm{ng} / \mathrm{mL}$ & 0 to $100 \mathrm{ng} / \mathrm{mL}$ \\
\hline $\begin{array}{l}\text { Arg Vasopressin } \\
\text { (AVP) }\end{array}$ & $\begin{array}{l}\text { Acetone and ether } \\
\text { procedure }\end{array}$ & $\begin{array}{l}\text { Arg8-Vasopressin enzyme } \\
\text { Immunoassay kit }\end{array}$ & $\begin{array}{l}\text { Assay Designs, Ann } \\
\text { Arbor, MI, USA. }\end{array}$ & $3.39 \mathrm{pg} / \mathrm{mL}$ & 3.39 to $1,000 \mathrm{pg} / \mathrm{mL}$ \\
\hline Copeptin & $\begin{array}{l}\text { C-18 SEP-column and } \\
\text { lyophilisation }\end{array}$ & $\begin{array}{l}\text { Copeptin enzyme } \\
\text { immunoassay kit }\end{array}$ & $\begin{array}{l}\text { R\&D Systems, } \\
\text { Minneapolis, } \\
\text { Minnesota, USA. }\end{array}$ & $18 \mathrm{pg} / \mathrm{mL}$ & 0 to $1,000 \mathrm{pg} / \mathrm{mL}$ \\
\hline SDF-1a & $\begin{array}{l}\text { Centrifuged for } \\
\text { complete platelet } \\
\text { removal }\end{array}$ & $\begin{array}{l}\text { SDF-1a enzyme } \\
\text { immunoassay }\end{array}$ & $\begin{array}{l}\text { R\&D Systems, } \\
\text { Minneapolis, } \\
\text { Minnesota, USA. }\end{array}$ & $18 \mathrm{pg} / \mathrm{mL}$ & 0 to $10,000 \mathrm{pg} / \mathrm{mL}$ \\
\hline Procalcitonin (PCT) & None & Immunoluminometric & $\begin{array}{l}\text { PCT LIA B.R.A.H.M.S } \\
\text { Diag } \\
\text { LLC, Georgia, USA }\end{array}$ & $0.3 \mathrm{ng} / \mathrm{mL}$ & 0.3 to $500 \mathrm{ng} / \mathrm{mL}$ \\
\hline
\end{tabular}

ACTH, adreno corticotropic hormone. AVP, arginine vasopressin. SDF-1a, stromal-derived factor-1 alpha. PCT, procalcitonin.

with healthy subjects, and a Chi-square test (or the Fisher's exact test when frequency was less than five) was selected for proportion comparisons. Correlations between molecular parameters were analyzed using the Spearman $r$ test. Models were built up sequentially starting with the variable most strongly associated with sepsis diagnosis and continuing until no other variable reached significance. When the final model was reached, each variable was dropped in turn to assess its effect. Different models were compared using the likehood ratio test, keeping in the final one variables significant at the $P=$ 0.05 level.

Different univariate logistic regression models were performed to evaluate which biological or clinical parameters can predict early sepsis diagnosis. Variables included in the analyses were: (i) cortisol baseline; ACTH, apelin, SDF-1 $\alpha$, AVP, copeptin, PCT (for molecular parameters), as well as (ii) age; APACHE II score, sepsis score, gender, shock on admission, (continuous variables for the three formers and binary for the two last parameters). Because normal distribution of biological values was not reached, the selected parameters were categorized: cutoffs values were determined by optimal likelihood ratios of individual receiver operating curve (ROC) analysis, or according to the manufacturer's recommendation for PCT.
Different multivariate logistic regression models with a stepwise selection procedure were then performed with categorical variables reaching significance in the univariate analysis. Different models were tested to compare the impact of PCT or sepsis score inclusions or not and areas under the ROC curves (AUC) were calculated both for the models and for each of the predictive variables, to compare if one model has one a better sensitivity/specificity than PCT or sepsis score alone. Optimal ROC curves were established with categorical variables, using a probability score to predict early sepsis diagnosis derived from a multivariate regression equation, as described by Shapiro et al [20]. The relationship between two parametric or non parametric variables was assessed using both InStat version 3.0 for basic between-group comparisons, SPSS version 16.0 (Chicago, IL, USA) for logistic regression analyses and MedCalc version 10 (Mariakerke, Belgium) for ROC calculations. $P \leq 0.05$ was considered statistically significant for all the performed tests.

\section{Results}

\section{General patient data}

General characteristics of the studied population and groups are detailed in Table 2. Given that it was an observational study, only the post hoc selected patients were included in the primary data analysis. 
Table 2: General characteristics of studied groups*

\begin{tabular}{|c|c|c|c|}
\hline & Non-septic $(n=37)$ & Septic $(n=37)$ & $P$-value \\
\hline Age & $60.2 \pm 15.3$ & $59.8 \pm 17$ & 0.9164 \\
\hline Gender (M/F) & $22 / 15$ & $22 / 15$ & 1.000 \\
\hline Apache II score & $18.8 \pm 8$ & $21.8 \pm 6.9$ & 0.082 \\
\hline Sepsis score $†$ & $6.5 \pm 3$ & $8.8 \pm 2.1$ & 0.0005 \\
\hline Albumin $\neq$ & $32.1 \pm 7.4$ & $23.5 \pm 5.1$ & 0.0001 \\
\hline Shock †† & 5 & 19 & 0.001 \\
\hline Lactates ₹ & 1.25 (0.94 to 2.5$)$ & 1.725 (1 to 3.9 ) & 0.2113 \\
\hline Kidney dysfunction $\S$ & 24 & 25 & 1.0000 \\
\hline \multicolumn{4}{|l|}{$\mathrm{CIRCI}^{* *}$} \\
\hline \multirow[t]{2}{*}{ baseline I } & 41 & 11 & 0.3575 \\
\hline & & & \\
\hline after corticotropin / & $3 /$ & $9 /$ & 0.1123 \\
\hline survivors/nonsurvivors & $3 / 4$ & $4 / 6$ & 1.0000 \\
\hline
\end{tabular}

CIRCl: critical illness-related corticosteroid insufficiency.

*: data are expressed as means $\pm S D$, number of patients or medians with interquartile ranges.

t: according to the 2001 SCCM/ESICM/ACCP/ATS/SIS International Sepsis

Definitions Conference [19].

$\dagger+$ : as defined by the need of (inotropic and/or vasopressive) catecholamines or mechanical device (for example, IABP) after at least $6 \mathrm{hrs}$ of initial resuscitation and in order to maintain mean arterial pressures $\geq 65 \mathrm{mmHg}$.

‡: Albumin (normal range 35 to $50 \mathrm{~g} / \mathrm{L}$ ), lactates (normal scale: 0.7 to $2.1 \mathrm{mmol} / \mathrm{L}$ ).

$\S$ according to the RIFLE criteria [21].

**: defined according to [4].

Healthy volunteers $(\mathrm{n}=14)$ exhibited a similar profile to the ICU-admitted patients (age: $62.6 \pm 3$ and gender: $6 /$ 8 ) and their blood albumin content was $46.6 \pm 0.5 \mathrm{~g} / \mathrm{L}$. Causes of MICU admission were: MI $(\mathrm{n}=11)$; haemorrhage $(\mathrm{n}=11)$, malignant arrhythmia $(\mathrm{n}=3)$, ischemia $(\mathrm{n}$ $=3)$, drug overdose $(n=2)$, others $(n=7)$ for the non-sepsis group; the sites/origins of sepsis were: lung $(n=21)$, urinary tract $(n=7)$, soft tissues $(n=5)$, others $(n=4)$ for the sepsis group. Microbiological cultures in the sepsis group revealed infections by Gram positive/Gram negative bacteria $(n=16 / 17)$, multiple bacterial strains $(n=3)$ and fungi $(\mathrm{n}=1)$. In-hospital mortality was $5 / 37$ and $10 /$ 37 patients in the non-sepsis and sepsis groups, respectively $(P=0.247)$.

\section{Blood cortisol and ACTH determinations, corticotropin (Cortrosyn ${ }^{\circ}$ ) response and $\mathrm{ACTH}$-to-cortisol ratio calculation}

High cortisol baseline on admission was associated with septic patients which displayed greater levels in comparison to non-septic patients and healthy volunteers $(P<$ 0.05 , Figure 2a). Correction for APACHE II scores still confirmed cortisol baseline as discriminant in early sepsis (unadjusted $\mathrm{OR}=5.12 ; P=0.005$ vs. adjusted $\mathrm{OR}=3.4 ; P$ $=0.048)$. However, septic patients and non-septic patients, as well as survivors/non-survivors, were not dis- criminated by excluding patients with evidence of CIRCI or by seeking the dynamic response of cortisol to corticotropin stimulation (NS). ACTH also displayed a differential profile with higher values in non-septic patients in comparison to septic patients and healthy volunteers $(P<$ 0.01 , Figure 2b). Consequently, an ACTH-to-cortisol ratio, as a marker of hypothalamo-pituitary-adrenal (HPA) corticotropic axis relationship [21], exemplified the dissociation between non-septic and septic values $(P$ $<0.001$, Figure 2c).

\section{Cortisol-to-albumin ratio calculation}

The cortisol-to-albumin ratio as a marker of free-cortisol index [22] was selective with the highest values in septic vs. non-septic patients and healthy volunteers $(P<$ 0.0001, Figure 2d).

\section{AVP, copeptin, APL, SDF-1 a blood levels and ratios}

Copeptin distinguished septic from non-septic patients better than AVP $(P<0.01$, Figure 3a, b). Copeptin-toAVP ratio, as an optimizing index, delineated decreased levels in non-septic MICU patients $(P<0.01$ vs. healthy volunteers, Figure $3 \mathrm{c})$. APL was slightly elevated in septic patients $(P<0.05$ vs. both non-septic patients and healthy volunteers, Figure 3d). SDF-1 $\alpha$ was increased in MICU patients with greater enhancement in septic patients 

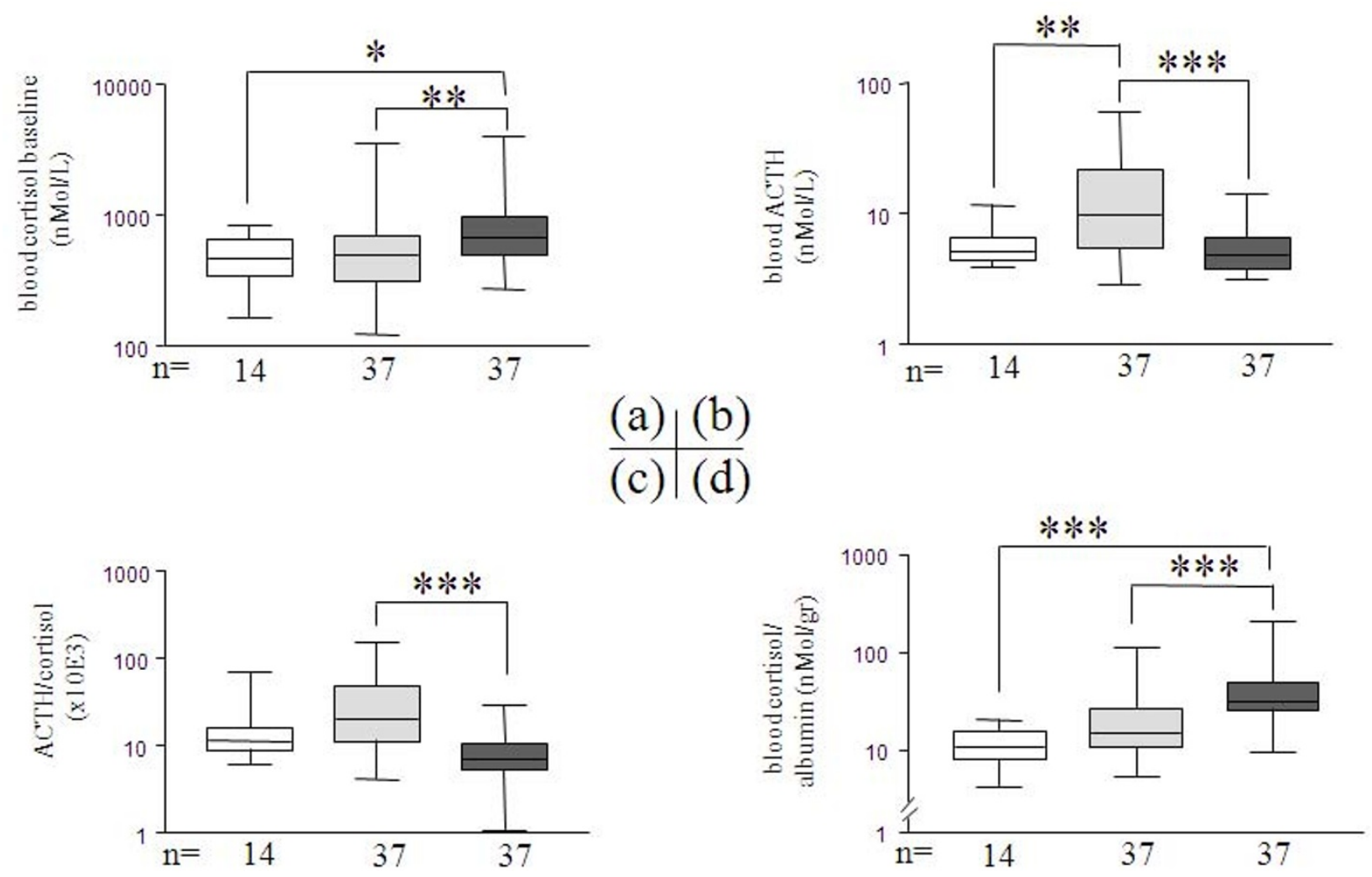

Figure 2 On ICU-admission blood concentrations of cortisol; ACTH; ACTH-to-cortisol and cortisol-to-albumin ratios. Three groups were compared: normal volunteers (white bars, $n=14$ ), non-septic ICU patients (light grey bars, $n=37$ ), septic ICU patients (dark grey bars, $n=37$ ). Graphs represent analysis (median, box $25^{\text {th }}$ to $75^{\text {th }}$ percentile range; error bars 10 th to $90^{\text {th }}$ percentile range) of (a) cortisol baseline (nMol/L), (b) $\mathrm{ACTH}(\mathrm{nMol} / \mathrm{L})$, (c) ACTH-to-cortisol ratio, (d) cortisol-to-albumin. The $Y$ axis is shown in logarithmic scale. $P$ is indicative of significant difference(s) between groups: *: $P \leq 0.05,{ }^{* *}: P \leq 0.01,{ }^{* * *}: P \leq 0.001$.

compared to both non-septic patients and healthy volunteers $(P<0.01$, Figure $4 \mathrm{a})$. The CXCR4 (SDF-1 $\alpha$ and MIF receptor) labeling pattern was scattered throughout P450-21hydroxylase-positive cells in the adrenocortical zona fasciculata. Intense punctiform staining was observed in regions surrounding adrenal vascular wall cells (Figure 4b, c).

\section{Circulating procalcitonin (PCT) content in critical illness}

Blood PCT was generally elevated in septic patients and remained distinctive from non-septic patients and healthy volunteers $(P<0.001$, Figure 5$)$. However, PCT was also greater in non-septic patients vs. healthy volunteers $(P<0.05$, Figure 5$)$.

\section{Correlations between SDF-1 1 /cortisol and AVP/cortisol}

SDF- $1 \alpha$ and AVP were positively correlated with their cortisol baseline counterpart level, in the overall study cohort (Figure 6), and in healthy volunteers after subgroup analysis (Figure 6 insert) for the former, and in the overall cohort and in ICU stress patients, with the stron- gest association observed in the nonseptic subset after subgroup analysis (Figure 7) for the later.

\section{Outcome value of neuro-corticotropic blood screening after MICU admission}

Three neuro-corticotropic blood parameters were significant distinctive biomarkers among survivors ( $\mathrm{n}=59,27$ sepsis vs. 32 non-sepsis) and non in-hospital- survivors (n $=15,10$ sepsis vs. 5 non-sepsis): copeptin, cortisol baseline, and cortisol-to-albumin ratio $(P=0.045 ; P=0.012 ; P$ $=0.0001$, respectively).

Prediction of sepsis diagnosis on ICU admission: usefulness of neuro-corticotropic blood screening in interpretative risk assessment and performance of a probability score Individual receiver operating curve (ROC) factor analysis of general and molecular parameters allowed to delineate thresholds for further logistic regression studies, and the cutoff point corresponding to the best separation of data with minimal false negative and positive results was selected for studying categorical parameters. Univariate 

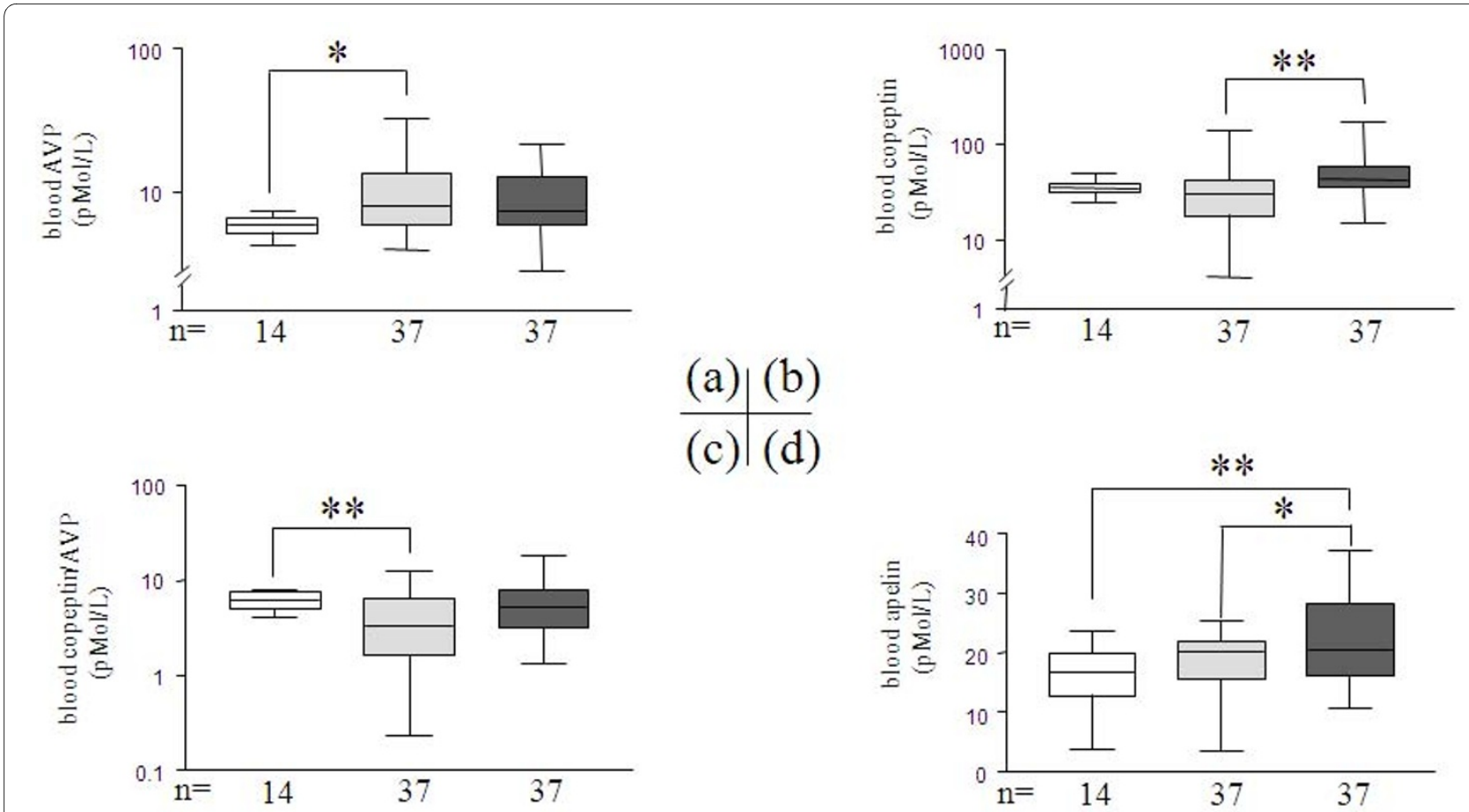

Figure 3 On ICU-admission blood concentrations of arginine-vasopressin (AVP); copeptin; copeptin-to-AVP ratio, and apelin (APL). The three groups were compared in bar charts as described in Figure 1, and represent (a) AVP (pMol/L), (b) copeptin (pMol/L), (c) copeptin-to-AVP ratio, (d) apelin (APL, pMol/L). The $Y$ axis is shown in logarithmic scale except for panel $F$ which is linear. $P$ is indicative of significant difference(s) between groups: $*: P \leq 0.05, * *: P \leq 0.01$.

analysis identified six factors relative to sepsis diagnosis on ICU admission (Table 3). In order to screen whether the presence of at least two variables will perform better than a single recommended gold standard parameter (that is, sepsis score or PCT) to predict sepsis on admission, two new combinations of at least two out of three variables have been created. One of these was performant if at least two out of the three categorized variables were positive (that is .ACTH $\leq 233 \mathrm{nMol} / \mathrm{L}$, cortisol baseline $\geq$ $450 \mathrm{nMol} / \mathrm{L}$ or PCT $>2 \mathrm{ng} / \mathrm{mL}$ ), with an OR much higher than PCT alone (Table 3) and an AUC of 0.845 (0.738 to $0.920,95 \% \mathrm{CI})$ vs. $0.726(0.607$ to $0.826,95 \% \mathrm{CI})(P=$ 0.035). The other one (that is, ACTH $\leq 233 \mathrm{nMol} / \mathrm{L}$, cortisol baseline $\geq 450 \mathrm{nMol} / \mathrm{L}$ or sepsis score $>7$ ) was also performant (Table 3) but AUCs were similar (0.811 (0.700 to $0.895,95 \% \mathrm{CI})$ vs. $0.727(0.607$ to $0.827,95 \% \mathrm{CI}), P=$ 0.076).

Different multivariate logistic regression with stepwise method were performed to identify which of the significant variables in the univariate analyse perform better to assess sepsis diagnosis on admission (Table 4). ROC analysis was used to represent the probability score predicting early sepsis diagnosis from equations and to compare different models of regression. A first model was performed with categorized sepsis score, and PCT as well as shock were excluded because already part of its calculation.
Another model was constructed by substituting sepsis score by PCT. These two models (M1 and 2) performed similarly (Table $4, P=0.494$ ) but were more efficient than the model (M3) including only categorized ACTH and cortisol baseline ( $P=0.036$ and $=0.0037$, respectively). The best AUCs are shown in Figure 8 .

\section{Discussion}

The present study highlights differentially profiled stress responses consecutive to ICU admission between septic and non-septic patients. Septic patients exhibited higher cortisol baseline but decreased blood ACTH-to-cortisol ratio, and higher SDF-1 $\alpha$, copeptin, and apelin on admission. Copeptin, cortisol baseline and ACTH on admission were higher in septic non-survivors, while SDF- $1 \alpha$ as well as AVP, in non-septic patients, was correlated with cortisol baseline. A probability score of biomarkers combining: baseline cortisol, $\mathrm{ACTH}$, and $\mathrm{PCT}$, was the best biological predictor of sepsis diagnosis and offers a substantial added value to each parameter individually or sepsis score.

\section{Corticotroph response to acute stress after ICU admission}

Total cortisol baseline is clearly elevated in critical illness, but its outcome value is confusing [23-29]. In this study, higher cortisol baseline was observed in non-survivors, 

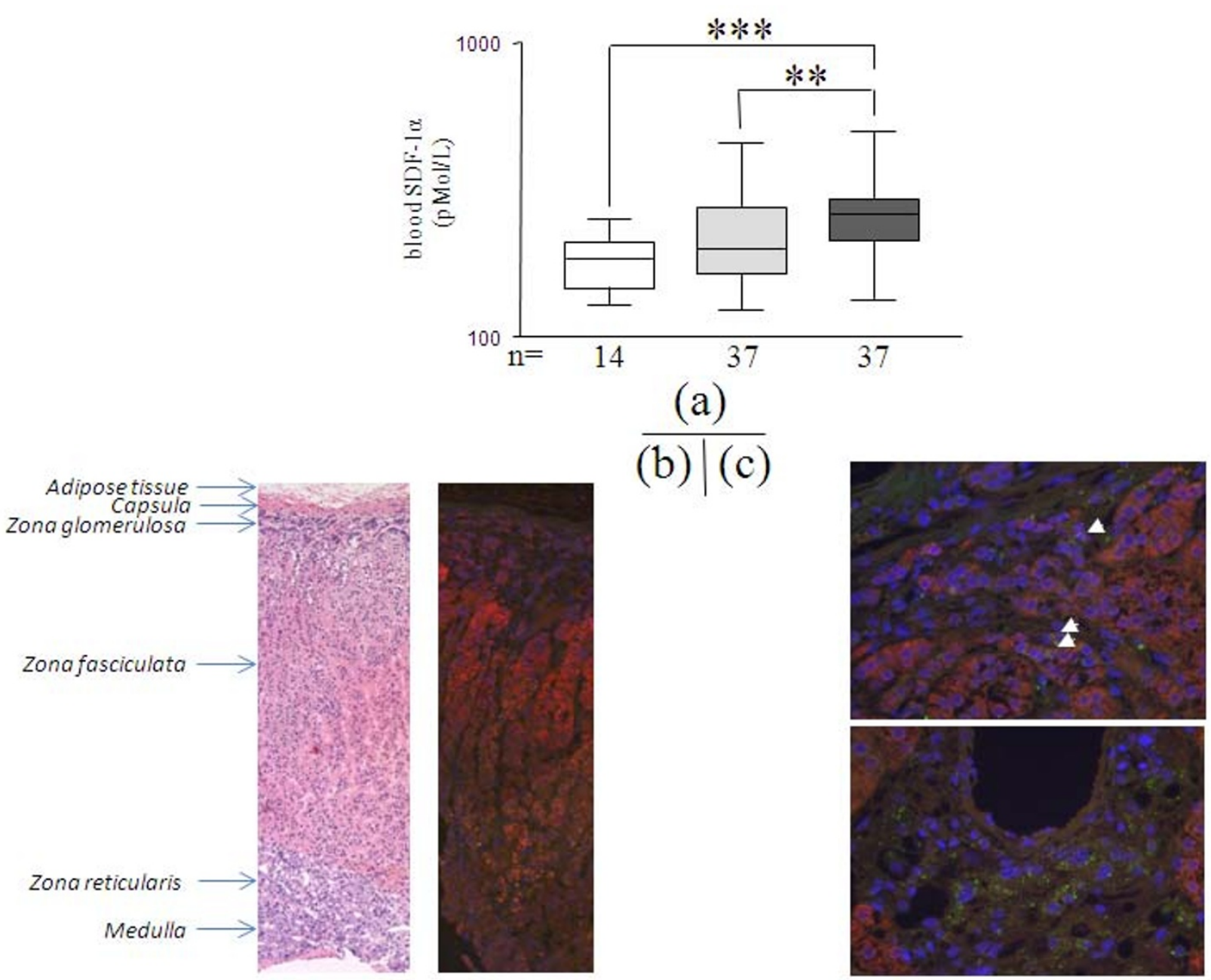

Figure 4 On ICU-admission blood concentrations of SDF-1a(CXCL-12) and expression of its receptor (CXCR4) in adrenal gland. The three groups were compared in bar charts as described in Figure 1, and represent (a) SDF-1a (pMol/L) in studied groups. The $Y$ axis is in logarithmic scale. $P$ are indicative of significant difference(s) between groups: ${ }^{*}: P<0.01$, ***: $P<0.001$. (b) low magnification of a human adrenal gland $(x 40)$ stained with H\&E; and after CP450-21-hydroxylase label (red), showing dominant specific expression in the zona fasciculata, (c) sparse expression of the SDF1a receptor CXCR4 (green labeling, white arrows) by CP450-21-hydroxylase expressing cells of a human adrenal gland cortex (zona fasciculata, red labeling, magnification $\times 400$ ) (upper panel), and dominant expression of CXCR4 (green labeling) by adrenal vascular wall cells, surrounded by CP45021-hydroxylase expressing clusters in zona fasciculata (red labeling, magnification × 400) (lower panel).

especially septic patients, as observed in large cohort studies $[30,31]$. The dynamic response of cortisol to corticotropin was not predictive of the outcome in our and other hands [23,27], in contradiction with the findings of Annane et al [5]. From these viewpoints, it appears imperative to thoroughly define study populations (that is, proper matching for period on inclusion, gender and age), sample timing, as well as to standardize methods of cortisol measurement, all being critical factors for comparisons.

Free cortisol index (FCI) has been advocated as a better determinant of the HPA status than cortisol in stressed patients [32], although not recommended for routine use by a recent international task force [4]. However, FCI requires cortisol binding globulin (CBG) measurement and total cortisol-to-albumin ratio can be an efficient and simplest surrogate marker [26,29,32-34]. In our study, total cortisol-to-albumin ratio was very high during acute sepsis and presented the best on admission outcome predictor.

\section{Differential dissociation of ACTH and cortisol in acute stress after ICU admission}

$\mathrm{ACTH}$-to-cortisol ratio dissociation, with low $\mathrm{ACTH}$ and high cortisol levels, is particularly observed during the chronic phase of critical illness [22], whereas high cortisol and ACTH have been observed during the initial phase $[35,36]$. Indeed, time-course and specificity of 


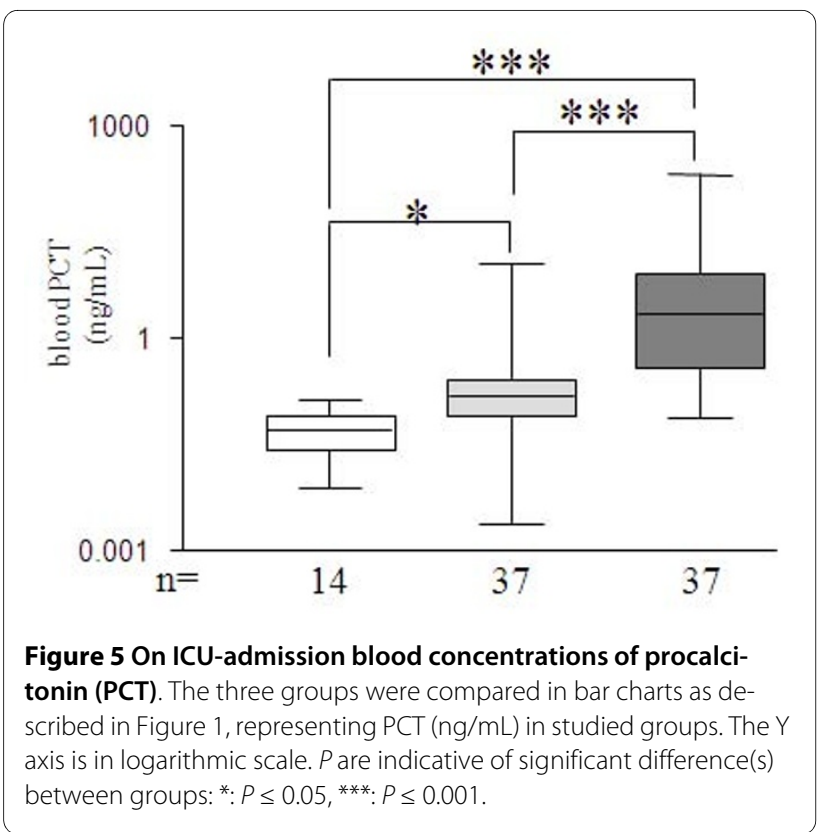

ACTH-to-cortisol dissociation are essential issues. In a small study [35], blood ACTH dramatically dropped in critically ill patients from Day 3 to 4, whereas cortisol remained high. An earlier dissociation was, however, observed on the first to second day in postoperative nonseptic cancerous patients [37]. Furthermore, although ACTH-to-cortisol baseline ratio was reported decreased in critically ill non-survivors [23,25], it was either found unchanged in septic non-survivors [24] or lowered in septic patients [26]. In this study, we found a decrease in ACTH-to-cortisol baseline ratio distinctive of sepsis among critically ill patients, as a result of both blunted ACTH content and elevated cortisol. This suggests nonpituitary-driven sources and non-ACTH regulators of cortisol release during acute sepsis or HPA axis alteration inducing secondary adrenal dysfunction with sustained increased blood cortisol as a result of tissue resistance or impaired clearance [38]. Moreover, systemically or locally released neurotransmitters (catecholamines, AVP), neuropeptides, inflammatory cytokines (including IL-1, IL-6, MIF) and growth factors have been committed in this respect $[38,39]$.

\section{Neuropeptides and the corticotropic HPA axis in acute stress after ICU admission}

SDF- $1 \alpha / C X C L 12$ colocalizes with AVP and APL in the magnocellular neurons of SON and PVN [12]. Centrally, SDF- $1 \alpha$ can autoregulate AVP release through its receptor $($ CXCR4) $[12,40]$. Systemically, SDF-1 $\alpha$ is released in

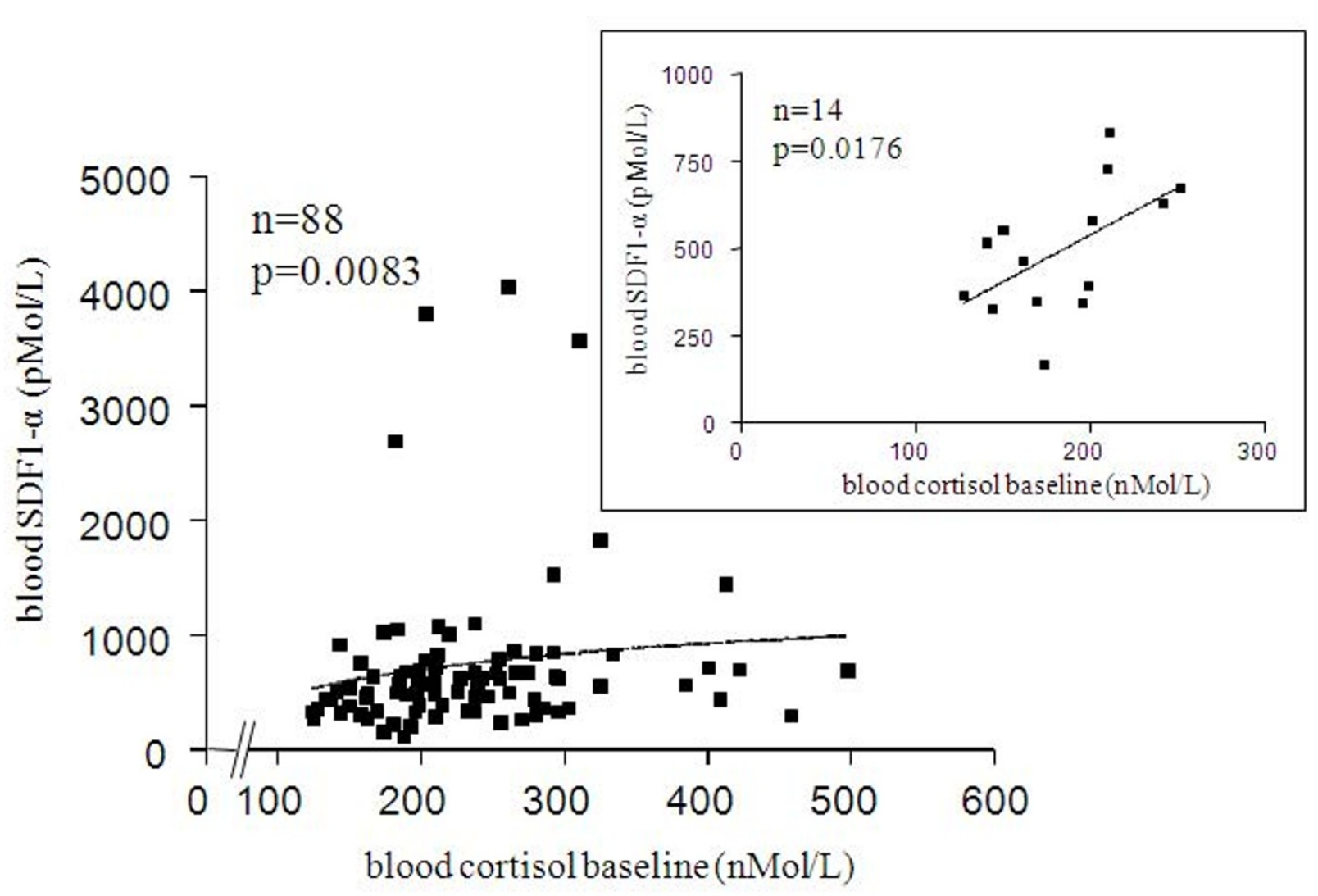

Figure 6 Correlation between blood SDF-1a and cortisol baseline. The overall studied population sample (including normal subjects) is shown included in the main panel: $r=0.2827$ ( $95 \% \mathrm{Cl}: 0.06899$ to 0.4717 ). The insert shows the strongest association between these two parameters found in healthy volunteers after subgroup analyses: $r=0.6220,(95 \% \mathrm{Cl}:-0.1191$ to 0.8709$)$. 


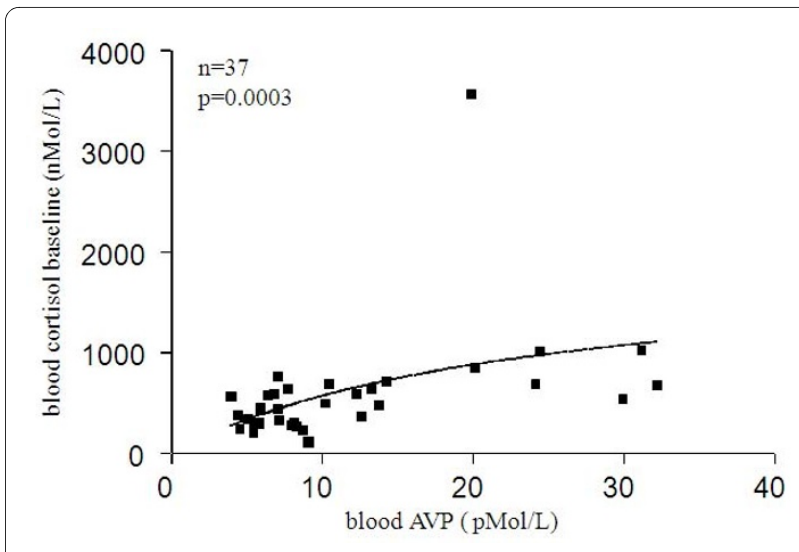

Figure 7 Correlation between blood AVP and cortisol baseline. The strongest association between these two parameters is shown in the non-septic ICU patient group: $r=0.5765$ ( $95 \%$ Cl: 0.2917 to 0.7674 ).

bloodstream early after critical illness initiation, and is associated with endothelial progenitor cell mobilization, sepsis-induced organ dysfunctions [41,42]. Indeed, in this study, blood SDF- $1 \alpha$ discriminated sepsis, as well as sepsis severity and outcome. A significant association was also found between blood SDF-1 $\alpha$ and cortisol baseline, and clusters of CXCR4-expressing cells scattered were observed within the adrenal corticosteroid productive area. This suggests the existence of a peripheral crosstalk between SDF-1 $\alpha$, CXCR4 (also alternative receptor to CD74 for MIF [43]) and the HPA corticotroph axis. Apelin (APL) is another counterpartner peptide with centrally-driven regulatory activities on AVP and ACTH release, and peripherally-driven diuretic and non-ACTHdependent cortisol release effects $[9,11]$. In this cohort of patients, blood APL was modestly elevated in critical illness, especially in sepsis, with no evidence of correlations found with either severity or outcome, nor with corticotroph HPA axis components.

Copeptin was also a more reliable diagnostic marker of sepsis than AVP in this study, as it was described as predictive of severity and outcome with more sustained blood levels than AVP in earlier works [12-16]. On the other hand, AVP was closely associated with cortisol baseline in our study, but only in non-septic ICU patients, further suggesting distinctive stress pathways in sepsis. Of note, higher blood AVP in septic shock has been observed with glucocorticoid administration [44] and a blunted cortisol response to corticotropin [45]. Also, a combination of glucocorticoids and AVP treatments was associated with improved survival and increased vasopressor-free days [44,46,47], as well as with reversal of AVP hyporesponsiveness in sheep [47]. This suggests a possible reset of sepsis-induced vascular V1aR down-regulation through the GRE receptor gene [48,49], and resurfaces a complex and often questioned link between AVP and corticosteroids, which is essentially disturbed in critical illness.

\section{A neurocorticotropic marker combination for sepsis diagnosis in acute stress after ICU admission}

Procalcitonin (PCT) is a known biochemical reference marker of sepsis diagnosis and severity [13,50,51], and sepsis score is a tentative summation of clinical and biochemical variables (including PCT) [18]. However, using the cutoff recommended by the manufacturer, PCT was not a perfect biomarker, as well as sepsis score, on diagnostic prediction. Conversely, a combination of the two categorized variables (cortisol baseline $\geq 450 \mathrm{nMol} / \mathrm{L}$, $\mathrm{ACTH} \leq 233 \mathrm{nMol} / \mathrm{L})$ performed equally to $\mathrm{PCT}(>2 \mathrm{ng} /$ $\mathrm{mL}$ ), and a predicted probability score for sepsis diagnosis using these all three categorical bio-variables (that is,

Table 3: Prediction of sepsis diagnosis on admission: univariate regression analyse* $(n=74$ patients)

\begin{tabular}{|c|c|c|}
\hline & $\begin{array}{c}\text { Odds Ratio (OR) } \\
\text { (lower to upper } 95 \% \mathrm{CI} \text { ) }\end{array}$ & $P$-value \\
\hline Cortisol baseline $\geq 450 \mathrm{nM} / \mathrm{L}$ & $5.120(1.623$ to 16.156$)$ & 0.004 \\
\hline Apache II score $\geq 14$ & $4.895(1.652$ to 14.503$)$ & 0.003 \\
\hline Shock & 5.454 (1.841 to 16.159$)$ & 0.001 \\
\hline Sepsis score $>7$ & 6.48 (2.34 to 17.952$)$ & 0.0002 \\
\hline $\mathrm{ACTH} \leq 233 \mathrm{nM} / \mathrm{L}$ & 7.041 (2.446 to 20.271$)$ & 0.0001 \\
\hline Procalcitonin $(P C T)>2 \mathrm{ng} / \mathrm{ml}$ & 16.889 (3.523 to 80.959$)$ & 0.0001 \\
\hline $\begin{array}{l}\text { At least two out of: cortisol, ACTH, sepsis } \\
\text { score } \dagger\end{array}$ & 19.200 (5.741 to 64.210$)$ & $<0.0001$ \\
\hline At least two out of: cortisol, ACTH, PCT † & $31.071(8.215$ to 117.516$)$ & $<0.0001$ \\
\hline
\end{tabular}

$\mathrm{ACTH}$, adreno corticotropic hormone; $\mathrm{Cl}$, confidence interval; $\mathrm{OR}$, odds ratio; $\mathrm{PCT}$, procalcitonin.

*: only significant factors are expressed $(P<0.05)$.

$t$ : according to individual cut-offs values. 
Table 4: Different models of logistic regression to predict sepsis diagnosis on admission * $(n=74$ patients $)$

\begin{tabular}{|c|c|c|c|}
\hline & AUC $(95 \% \mathrm{Cl})$ & OR $(95 \% \mathrm{CI})$ & $P$-value \\
\hline \multicolumn{4}{|l|}{ Model 1 (M1) } \\
\hline $\mathrm{ACTH} \leq 233 \mathrm{nM} / \mathrm{L}$ & 0.875 (0.774 to 0.942$)$ & 9.192 (2.466 to 34.265 ) & 0.001 \\
\hline $\begin{array}{l}\text { Cortisol baseline } \geq 450 \\
n M / L\end{array}$ & & 4.279 (1.007 to 18.181$)$ & 0.049 \\
\hline Sepsis score $>7$ & & 5.371 ( 1.567 to 18.404$)$ & 0.007 \\
\hline \multicolumn{4}{|l|}{ Model 2 (M2) } \\
\hline $\mathrm{ACTH} \leq 233 \mathrm{nM} / \mathrm{L}$ & 0.903 (0.808 to 0.960$)$ & 21.16 (4.252 to 105.307$)$ & 0.0002 \\
\hline $\begin{array}{l}\text { Cortisol baseline } \geq 450 \\
\mathrm{nM} / \mathrm{L}\end{array}$ & & 8.81 (1.616 to 48.037 ) & 0.012 \\
\hline $\begin{array}{l}\text { Procalcitonin }(\mathrm{PCT})>2 \\
\mathrm{ng} / \mathrm{mL}\end{array}$ & & 28.558 (4.393 to 185.636$)$ & 0.0004 \\
\hline \multicolumn{4}{|l|}{ Model 3 (M3) } \\
\hline $\mathrm{ACTH} \leq 233 \mathrm{nM} / \mathrm{L}$ & 0.805 (0.693 to 0.890$)$ & 9.125 (2.667 to 31.218 ) & 0.0004 \\
\hline $\begin{array}{l}\text { Cortisol baseline } \geq 450 \\
n M / L\end{array}$ & & 7.457 (1.89 to 29.426$)$ & 0.004 \\
\hline \multicolumn{4}{|l|}{ Model 4 (M4) } \\
\hline $\begin{array}{l}\text { Procalcitonin }(\mathrm{PCT})>2 \\
\mathrm{ng} / \mathrm{mL}\end{array}$ & 0.726 (0.607 to 0.826$)$ & 16.889 (3.523 to 80.959 ) & 0.0004 \\
\hline \multicolumn{4}{|l|}{ Model 5 (M5) } \\
\hline Sepsis score $>7$ & 0.727 (0.607 to 0.827$)$ & 6.481 (2.34 to 17.952$)$ & 0.0003 \\
\hline
\end{tabular}

$\mathrm{ACTH}$, adreno corticotropic hormone; $\mathrm{AUC}$, area under the receiver operating characteristic curve; $\mathrm{Cl}$, confidence interval; $\mathrm{OR}$ : odds ratio; $\mathrm{PCT}$, procalcitonin.

categorized PCT or sepsis score) substantially improved the initial prediction of sepsis diagnosis in this cohort.

\section{Limitations of the study}

This study is observational and somewhat limited because of the nominal number of included patients, although thoroughly matched with regard to timing inclusion and general characteristics of the study population. Although our initial gold standard diagnosis for sepsis was a clinical one with a relatively low likelihood ratio, it was further validated by a microbiological confirmation, but re-allocations were mandatory. Selection of parameters, especially neurocorticotropic markers, while arbitrary, was nonetheless based on recent knowledge relative to coexpression of studied neuropeptides and cytokines (SDF-1 $\alpha$, AVP, copeptin, APL) in the CNS. A not-highly sensitive PCT measurement has been selected. In the multiple regression analysis, the use of more than three variables with a limited sample did not definitely avoid possible overfitting. The alternative diagnostic combination of parameters (cortisol baseline, ACTH) proposed to challenge PCT measurement in early sepsis diagnosis is not necessarily always easier or faster to obtain in all centers. Of course, a larger study should fur- ther validate the diagnostic usefulness of this biomarker combination.

\section{Conclusions}

The neuro-corticotropic systemic stress response of early admitted ICU patients is differentially profiled with special emphasis on sepsis. An alternative diagnostic combination of categorical parameters (cortisol baseline, $\mathrm{ACTH}$ ) was as efficient as PCT or sepsis score in identifying critical sepsis, and all together offered the best performance. This might help ICU physicians in refining bedside diagnostic tools, in addition to traditional microbiological sampling and decision-making strategies, and calls for further validation on a larger population.

\section{Key messages}

- The neuro-corticotropic stress response (ACTH/ cortisol baseline, copeptin, apelin, SDF-1 $\alpha$ ) is in someway different in septic vs. non-septic early admitted ICU patients.

- Adding cortisol baseline and ACTH to PCT blood measurement or sepsis score -gold standards- in a combination of variable score analyses helps in refining bedside diagnostic tools to efficiently diagnose sepsis. 


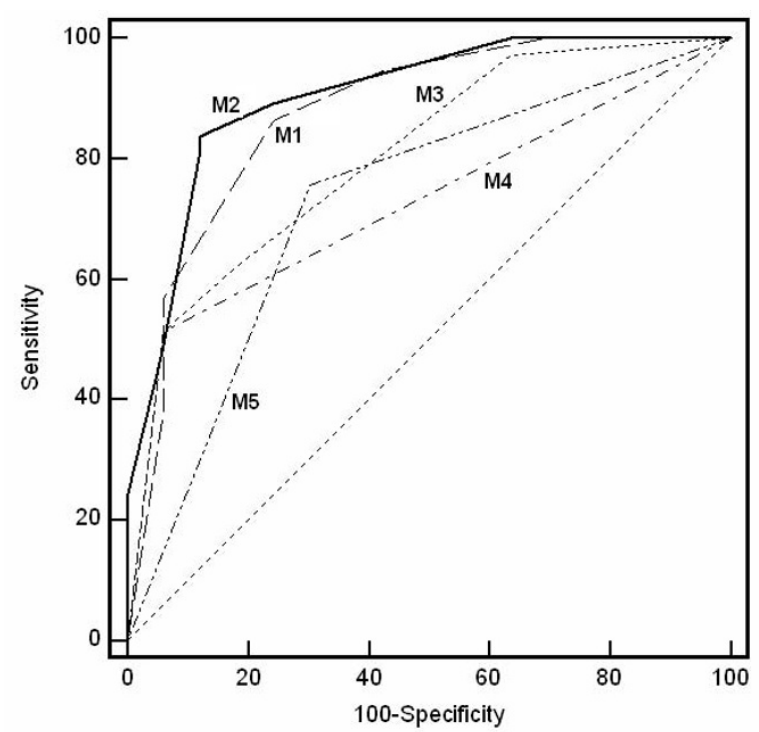

Figure 8 Comparative Receiver operating characteristic curves for early sepsis diagnosis. The curves relate the different models of logistic regression detailed in Table 4: $\mathbf{M} \mathbf{1}$ : sepsis score $>7 ; \mathrm{ACTH} \leq 233$ $\mathrm{nM} / \mathrm{L}$; cortisol $\geq 450 \mathrm{nM} / \mathrm{L}, \mathbf{M 2}$ : PCT $>2 \mathrm{ng} / \mathrm{mL}$; ACTH $\leq 233 \mathrm{nM} / \mathrm{L}$; cortisol $\geq 450 \mathrm{nM} / \mathrm{L}, \mathbf{M 3}$ : ACTH $\leq 233 \mathrm{nM} / \mathrm{L}$; cortisol $\geq 450 \mathrm{nM} / \mathrm{L}, \mathbf{M} 4$ : PCT $>2 \mathrm{ng} / \mathrm{mL}$, M5: sepsis score $>7$. Sepsis score is a recommended clinicobiological multiple variable score [17,18], ACTH and cortisol baseline are a combination of two HPA biological stress parameters, and blood PCT is a gold standard biological marker of sepsis [13,50]. Respective AUC values are expressed in Table 4. The three combination panels including the two selected gold standards: sepsis score or PCT (in M1 and M2), performed for the best and similarly and offered added-value to each selected gold standard individually (that is, sepsis score (in M5) or $P C T$ (in M4)): $P=0.005$ and $P<0.001$, respectively. On the other hand, adding sepsis score or PCT to the two combinations of stress parameters (ACTH, cortisol baseline) also optimized the prediction vs. ACTH and cortisol baseline: $P=0.037$ and $P=0.036$, respectively. Vertical axis represents the number of true positive values (sensitivity) and horizontal axis the number of false positive values (1-specificity), with the diagonal segments produced by ties.

\section{Abbreviations}

ACTH: adreno corticotropic hormone; APL: apelin; AUC: area under the curve; AVP: arginine vasopressin; CBG: cortisol binding globulin; CIRCl: critical illnessrelated corticosteroid insufficiency; CNS: central nervous system; CORTICUS: Corticosteroid therapy of septic shock study; CRH: corticotrophin-releasing hormone; CXCR4: C-X-C chemokine receptor type 4; FCl: free cortisol index; GRE: glucocorticoid response element; HPA: hypothalamo pituitary adrenal; MIF: Macrophage migration Inhibitory Factor; (M)ICU: (Medical) Intensive Care Unit; MI: myocardial infarct; PCT: procalcitonin; PVN: paraventricular nuclei; ROC: receiver operating characteristic; SDF-1a: stromal-derived factor-1 alpha; SIRS: systemic inflammatory response syndrome; SON: supraoptic.

\section{Competing interests}

The authors declare that they have no competing interests.

\section{Authors' contributions}

$\mathrm{OL}, \mathrm{JFR}, \mathrm{FC}, \mathrm{NG}-\mathrm{P}, \mathrm{RD}, \mathrm{PS}$ and $\mathrm{AC}$ participated in the study design. OL, JFR, FC, LC and $\mathrm{BH}$ performed the study. OL, JFR, FC and LC processed the data and performed the statistical analysis. OL and FC wrote the manuscript. All authors read and approved the final manuscript.

\section{Acknowledgements}

The authors thank the MICU nursing staff for sample collection, Nathalie Carrier (CRC) for the statistical analysis, and Nicolas Beaudet for helpful comments.

\section{Author Details}

'Soins intensifs médicaux, département de Médecine, Université de Sherbrooke, 3001, 12th Avenue Nord, Sherbrooke, QC J1H 5N4, Canada, 2Centre de recherche clinique Étienne-Lebel (CRCEL) CHUS, Université de Sherbrooke, 3001, 12th Avenue Nord, Sherbrooke, QC J1H 5N4, Canada and ${ }^{3}$ Département de Physiologie et Biophysique, Université de Sherbrooke, 3001 , 12th Avenue Nord, Sherbrooke, QC J1H 5N4, Canada

Received: 21 September 2009 Revised: 3 February 2010 Accepted: 9 July 2010 Published: 9 July 2010

\section{References}

1. Angus DC, Linde-Zwirble WT, Lidicker J, Clermont G, Carcillo J, Pinsky MR: Epidemiology of severe sepsis in the United States: analysis of incidence, outcome, and associated costs of care. Crit Care Med 2001, 29:1303-1310.

2. Abraham E, Singer M: Mechanism of sepsis-induced organ dysfunction. Crit Care Med 2007, 35:2408-2416.

3. Maxime V, Siami S, Annane D: Metabolism modulators in sepsis: the abnormal pituitary response. Crit Care Med 2007, 35:S596-S601.

4. Marik PE, Pastores SM, Annane D, Meduri GU, Sprung CL, Arlt W, Keh D, Briegel J, Beishuizen A, Dimopoulou I, Tsagarakis S, Singer M, Chrousos GP, Zaloga G, Bokhari F, Vogeser M: Recommendations for the diagnosis and management of corticosteroid insufficiency in critically ill adult patients: consensus statements from an international task force by the American College of Critical Care Medicine. Crit Care Med 2008, 36:1937-1949.

5. Annane D, Sebille V, Troche G, Raphael JC, Gajdos P, Bellissant E: A 3-level prognostic classification in septic shock based on cortisol levels and cortisol response to corticotropin. JAMA 2000, 283:1038-1045.

6. Annane D, Sebille V, Charpentier C, Bollaert PE, Francois B, Korach JM, Capellier G, Cohen Y, Azoulay E, Troche G, Chaumet-Riffaud P, Bellissant E: Effect of treatment with low doses of hydrocortisone and fludrocortisone on mortality in patients with septic shock. JAMA 2002, 288:862-871.

7. Sprung CL, Annane D, Keh D, Moreno R, Singer M, Freivogel K, Weiss YG, Benbenishty J, Kalenka A, Forst H, Laterre PF, Reinhart K, Cuthbertson BH, Payen D, Briegel J: Hydrocortisone therapy for patients with septic shock. N Engl J Med 2008, 358:111-124.

8. Aguilera G, Rabadan-Diehl C: Vasopressinergic regulation of the hypothalamic-pituitary-adrenal axis: implications for stress adaptation. Regul Pept 2000, 96:23-29.

9. Gallo-Payet N, Roussy JF, Chagnon F, Roberge C, Lesur O: Hypothalamicpituitary-adrenal axis and MODS in critical illness: special focus on arginine-vasopressin (AVP) and apelin (APL). Journal of Organ Dysfunction 2008, 4:216-229.

10. Tatemoto K, Hosoya M, Habata Y, Fujii R, Kakegawa T, Zou MX, Kawamata Y, Fukusumi S, Hinuma S, Kitada C, Kurokawa T, Onda H, Fujino M: Isolation and characterization of a novel endogenous peptide ligand for the human APJ receptor. Biochem Biophys Res Commun 1998, 251:471-476

11. Llorens-Cortes C, Moos F: Opposite potentiality of hypothalamic coexpressed neuropeptides, apelin and vasopressin in maintaining body fluid homeostasis. Prog Brain Res 2008, 170:559-570.

12. Callewaere C, Banisadr G, Desarmenien MG, Mechighel P, Kitabgi $P$, Rostene WH, Melik Parsadaniantz S: The chemokine SDF-1/CXCL12 modulates the firing pattern of vasopressin neurons and counteracts induced vasopressin release through CXCR4. Proc Natl Acad Sci USA 2006, 103:8221-8226.

13. Schuetz $P$, Christ-Crain M, Muller B: Biomarkers to improve diagnostic and prognostic accuracy in systemic infections. Curr Opin Crit Care 2007, 13:578-585.

14. Struck J, Morgenthaler NG, Bergmann A: Copeptin, a stable peptide derived from the vasopressin precursor, is elevated in serum of sepsis patients. Peptides 2005, 26:2500-2504

15. Jochberger S, Velik-Salchner C, Mayr VD, Luckner G, Wenzel V, Falkensammer G, Ulmer H, Morgenthaler N, Hasibeder W, Dunser MW: The vasopressin and copeptin response in patients with vasodilatory shock after cardiac surgery: a prospective, controlled study. Intensive Care Med 2009, 35:489-497.

16. Jochberger S, Morgenthaler NG, Mayr VD, Luckner G, Wenzel V, Ulmer H, Schwarz S, Hasibeder WR, Friesenecker BE, Dunser MW: Copeptin and 
arginin vasopressin concentrations in critically ill patients. J Clin Endocrinol Metab 2006, 91:4381-4386.

17. Levy MM, Fink MP, Marshall JC, Abraham E, Angus D, Cook D, Cohen J, Opal SM, Vincent JL, Ramsay G, SCCM/ESICM/ACCP/ATS/SIS: 2001 SCCM/ ESICM/ACCP/ATS/SIS International Sepsis Definitions Conference. Crit Care Med 2003, 31:1250-1256.

18. Dellinger RP, Levy MM, Carlet JM, Bion J, Parker MM, Jaeschke R, Reinhart K, Angus DC, Brun-Buisson C, Beale R, Calandra T, Dhainaut JF, Gerlach H, Harvey M, Marini JJ, Marshall JC, Ranieri M, Ramsay G, Sevransky J, Thompson T, Townsend S, Vender JS, Zimmerman, Vincent JL: Surviving Sepsis Campaign quidelines: International guidelines for management of severe sepsis and septic shock. Crit Care Med 2008, 36:296-327.

19. Lauzier F, Levy B, Lamarre P, Lesur O: Vasopressin or norepinephrine in early hyperdynamic septic shock: a randomized clinical trial. Intensive Care Med 2006, 32:1782-1789.

20. Shapiro NI, Trzeciak S, Hollander JE, Birkhahn R, Otero R, Osborn TM, Moretti E, Nguyen HB, Gunnerson KJ, Milzman D, Gaieski DF, Goyal M, Cairns CB, Ngo L, Rivers EP: A prospective, multicenter derivation of a biomarker panel to assess risk of organ dysfunction, shock, and death in emergency department patients with suspected sepsis. Crit Care Med 2009, 37:96-104.

21. Hoste EA, Clermont G, Kersten A, Venkataraman R, Angus DC, De Bacquer D, Kellum JA: RIFLE criteria for acute kidney injury are associated with hospital mortality in critically ill patients: a cohort analysis. Crit Care 2006, 10:R73.

22. Bornstein SR, Engeland WC, Ehrhart-Bornstein M, Herman JP: Dissociation of ACTH and glucocorticoids. Trends Endocrinol Metab 2008, 19:175-180.

23. Dimopoulou I, Stamoulis K, llias I, Tzanela M, Lyberopoulos P, Orfanos S, Armaganidis A, Theodorakopoulou M, Tsagarakis S: A prospective study on adrenal cortex responses and outcome prediction in acute critical illness: results from a large cohort of 203 mixed ICU patients. Intensive Care Med 2007, 33:2116-2121.

24. Marx C, Petros S, Bornstein SR, Weise M, Wendt M, Menschikowski M, Engelmann L, Hoffken G: Adrenocortical hormones in survivors and nonsurvivors of severe sepsis: diverse time course of dehydroepiandrosterone, dehydroepiandrosterone-sulfate, and cortisol. Crit Care Med 2003, 31:1382-1388.

25. Dunser MW, Hasibeder WR, Wenzel V, Schwarz S, Ulmer H, Knotzer H, Pajk W, Friesenecker BE, Mayr AJ: Endocrinologic response to vasopressin infusion in advanced vasodilatory shock. Crit Care Med 2004 , 32:1266-1271.

26. Annane D, Maxime V, Ibrahim F, Alvarez JC, Abe E, Boudou P: Diagnosis of adrenal insufficiency in severe sepsis and septic shock. Am J Respir Crit Care Med 2006, 174:1319-1326

27. Riche FC, Boutron CM, Valleur P, Berton C, Laisne MJ, Launay JM, Chappuis $P$, Peynet J, Vicaut E, Payen D, Cholley BP: Adrenal response inpatients with septic shock of abdominal origin: relationship to survival. Intensive Care Med 2007, 33:1761-1766.

28. Venkatesh B, Cohen J, Hickman I, Nisbet J, Thomas P, Ward G, Hall J, Prins J: Evidence of altered cortisol metabolism in critically ill patients: a prospective study. Intensive Care Med 2007, 33:1746-1753.

29. Bendel S, Karlsson S, Pettila V, Loisa P, Varpula M, Ruokonen E, Finnsepsis Study Group: Free cortisol in sepsis and septic shock. Anesth Analg 2008, 106:1813-1819.

30. Lipinier-Fredman D, Sprung CL, Laterre PF, Weiss Y, Goodman SV Vogeser M, Briegel J, Keh D, Singer M, Moreno R, Bellissant E, Annane D, Corticus Study Group: Adrenal function in sepsis: the retrospective Corticus cohort study. Crit Care Med 2007, 35:1012-1018.

31. Karlsson S, Varpula M, Ruokonen E, Pettila V, Parviainen I, Ala-Kokko TI, Kolho E, Rintala EM: Incidence, treatment, and outcome of severe in ICU-treated adults in Finland: the Finnsepsis study. Intensive Care Med 2007, 33:435-443.

32. Le Roux CW, Chapman GA, Kong WM, Dhillo WS, Jones J, AlaghbandZadeh J: Free cortisol index is better than serum total cortisol in determining hypothalamic-pituitary-adrenal status in patients undergoing surgery. J Clin Endocrinol Metab 2003, 88:2045-2048.

33. Ho JT, Al-Musalhi H, Chapman MJ, Quach T, Thomas PD, Bagley CJ, Lewis JG, Torpy DJ: Septic shock and sepsis: a comparison of total and free plasma cortisol levels. J Clin Endocrinol Metab 2006, 91:105-114.

34. Nicholson JP, Wolmarans MR, Park GR: The role of albumin in critical illness. Br J Anaesth 2000, 85:599-610.
35. Vermes I, Beishuizen A, Hampsink RM, Haanen C: Dissociation of plasma adrenocorticotropin and cortisol levels in critically ill patients: possible role of endothelin and atrial natriuretic hormone. J Clin Endocrino Metab 1995, 80:1238-1242.

36. Van den Berghe GH: The neuroendocrine stress response and modern intensive care: the concept revisited. Burns 1999, 25:7-16.

37. Cho YM, Kim SY, CHO BY, Lee HK, Yang HK, Lee KU: Dissociation between plasma adrenocorticotropin and serum cortisol level during the early postoperative period after gastrectomy. Horm Res 2000, 53:246-250

38. Bornstein SR, Chrousos GP: Clinical review 104: Adrenocorticotropin (ACTH)- and non-ACTH-mediated regulation of the adrenal cortex: neural and immune inputs. J Clin Endocrinol Metab 1999, 84:1729-1736.

39. Marx C, Ehrhart-Bornstein M, Scherbaum WA, Bornstein SR: Regulation of adrenocortical function by cytokines-relevance for immune endocrine interaction. Horm Metab Res 1998, 30:416-420.

40. Barbieri F, Bajetto A, Porcile C, Pattarozzi A, Scettini G, Florio T: Role of stromal cell-derived factor 1 (SDF1/CXCL12) in regulating anterior pituitary function. J Mol Endocrinol 2007, 38:383-389.

41. Becchi C, Pillozzi S, Fabbri LP, Al Malyan M, Cacciapuoti C, Della Bella C, Nucera M, Masselli M, Boncinelli S, Arcangeli A, Amedei A: The increase of endothelial progenitor cells in the peripheral blood: a new parameter for detecting onset and severity of sepsis. Int J Immunopathol Pharmacol 2008, 21:697-705

42. Cribbs S, Rojas M, Taylor R: Circulating endothelial progenitor cells are inversely associated with respiratory organ dysfunction in sepsis. Crit Care Med 2008, 36:A76.

43. Bernhagen J, Krohn R, Lue H, Gregory JL, Zernecke A, Koenen RR, Dewor M, Georgiev I, Schober A, Leng L, Kooistra T, Fingerle-Rowson G, Ghezzi P, Kleemann R, McColl SR, Bucala R, Hickey MJ, Weber C: MIF is a noncognate ligand of CXC chemokine receptors in inflammatory and atherogenic cell recruitment. Nat Med 2007, 13:587-596.

44. Russel JA, Walley KR, Gordon AC, Cooper DJ, Hebert PC, Singer J, Holmes CL, Mehta S, Granton JT, Storms MM, Cook DJ, Presneill J, Dieter Ayers for the Vasopressin and Septic Shock Trial Investigators: Interaction of vasopressin infusion, corticosteroid treatment, and mortality of septic shock. Crit Care Med 2009, 37:811-818.

45. Sharshar T, Blanchard A, Paillard M, Raphael JC, Gajdos P, Annane D: Circulating vasopressin levels in septic shock. Crit Care Med 2003, 31:1752-1758

46. Bauer SR, Lam SW, Cha SS, Oyen LJ: Effect of corticosteroids on arginine vasopressin-containing vasopressor therapy for septic shock: a case control study. J Crit Care 2008, 23:500-506.

47. Ertmer C, Bone HG, Morelli A, Van Aken H, Erren M, Lange M, Traber DL, Westphal M: Methylprednisolone reverses vasopressin hyporesponsiveness in ovine endotoxemia. Shock 2007, 27:281-288.

48. Bucher M, Hobbhahn J, Taeger K, Kurtz A: Cytokine-mediated downregulation of vasopressin $\mathrm{V}(1 \mathrm{~A})$ receptors during acute endotoxemia in rats. Am J Physiol Regul Integr Comp Physiol 2002, 282:R979-R984.

49. Watters JJ, Swank MW, Wilkinson CW, Dorsa DM: Evidence for glucocorticoid regulation of the rat vasopressin $\mathrm{V} 1$ a receptor gene. Peptides 1996, 17:67-73.

50. Ugarte H, Silva E, Mercan D, De Mendonca A, Vincent JL: Procalcitonin used as a marker of infection in the intensive care unit. Crit Care Med 1999, 27:498-504

51. Christ-Crain M, Stolz D, Jutla S, Couppis O, Muller C, Bingisser R, Schuetz P, Tamm M, Edwards R, Muller B, Grossman AB: Free and total cortisol levels as predictors of severity and outcome in community-acquired pneumonia. Am J Respir Crit Care Med 2007, 176:913-920.

doi: $10.1186 /$ cc9102

Cite this article as: Lesur et al., Proven infection-related sepsis induces a differential stress response early after ICU admission Critical Care 2010, 14:R13 